\title{
Pancreatic cancer survival in central and northern Denmark from 1998 through 2009: a population- based cohort study
}

This article was published in the following Dove Press journal:

Clinical Epidemiology

19 July 2011

Number of times this article has been viewed

\author{
Deirdre P Cronin-Fenton' \\ Rune Erichsen' \\ Frank V Mortensen ${ }^{2}$ \\ Sarunas Dikinis ${ }^{3}$ \\ Mette Nørgaard' \\ Jacob Jacobsen' \\ 'Department of Clinical Epidemiology, \\ Aarhus University Hospital, Denmark; \\ ${ }^{2}$ Department of Gastrointestinal \\ Surgery L, Aarhus University \\ Hospital, Denmark; ${ }^{3}$ Department of \\ Gastrointestinal Surgery A, Aalborg \\ Hospital, Aarhus University Hospital, \\ Denmark
}

Correspondence: DP Cronin-Fenton Department of Clinical Epidemiology, Aarhus University, Olof Palmes Alle 43-46, 8200 Aarhus N., Denmark $\mathrm{Tel}+45-894248 \mathrm{I} 6$

Fax +45-8942480 I

Email dc@dce.au.dk
Objectives: Pancreatic cancer has a relatively low incidence but ranks fourth among cancer-related deaths in western countries. In Denmark, cancer survival generally is lower than in other countries with comparable health care systems. As a result, in 2000, a national strategy to improve cancer survival was introduced. Here we examine time trends in survival and relative mortality among pancreatic cancer patients, using Danish population and medical databases.

Methods: Using the Danish National Patient Registry (DNPR), we identified all incident pancreatic cancer patients $(n=2968)$ diagnosed between 1998 and 2009 in the Central and North Denmark Regions. We computed the 1-, 3-, and 5-year survival and relative mortality (MRR) and associated 95\% confidence intervals (CI) adjusting for age and gender. Among surgical patients, we also computed 30-day mortality and 30-day MRR.

Results: Median age at diagnosis was approximately 71 years. The annual number of patients increased from 189 in 1998-2000 to 302 in 2007-2009. There was a slight improvement in 1-, 3 -, and 5-year survival over time from $14.8 \%$ to $17.7 \%$; $3.5 \%$ to a predicted $5.6 \%$; and from $2.0 \%$ to a predicted $3.8 \%$, from $1998-2000$ to $2007-2009$, respectively. Correspondingly, the adjusted relative mortality decreased from 1998-2000 to 2007-2009. Thirty-day post-operative mortality decreased from $12.2 \%$ in $1998-2000$ to $5.8 \%$ in 2007-2009, corresponding to a 30-day MRR of $0.38,95 \% \mathrm{CI}=0.09,1.6$ in 2007-2009.

Conclusion: There was a slight, albeit modest, improvement in survival and relative mortality in pancreatic cancer patients between 1998 and 2009. As we lacked staging information, it is not clear if this improvement is attributable to earlier stage at diagnosis. However, these improvements likely reflect the national cancer strategy which aimed to centralize cancer services and involved the introduction of palliative and adjuvant chemotherapy for pancreatic cancer in Denmark. The dismal prognosis of pancreatic cancer means that efforts to improve survival need to be intensified.

Keywords: pancreatic cancer, survival, relative mortality, epidemiology

\section{Introduction}

Pancreatic cancer is a rapidly progressing disease with a dismal prognosis. It ranks as the fourth leading cause of cancer-related death in developed countries. ${ }^{1}$ In 2008 alone, the standardized incidence rate (standardized to a world standard) of pancreatic cancer worldwide was 3.9 per 100,000 persons while the standardized (world standard) mortality rate was only slightly lower at 3.7 per 100,000 persons. ${ }^{1}$ In Denmark, the incidence rate was 15 and 17 per 100,000 women and men, respectively, ${ }^{2}$ and that of mortality was 14.4 and 16.2 per 100,000, respectively (standardized to the Danish population 2000). ${ }^{3}$ The disease has an insidious onset with relatively nonspecific symptoms. ${ }^{4}$ As a result, the majority of patients are diagnosed at an advanced stage, ${ }^{5-7}$ limiting the possibility of 
curative treatment. ${ }^{8}$ Surgery remains the only curative treatment for pancreatic cancer. ${ }^{9}$ However, research indicates that less than $20 \%$ of patients are suitable surgical candidates. ${ }^{8}$

In the US, survival from most cancers has significantly improved between 1950 and $1995,{ }^{10}$ likely facilitated by technological advances enabling earlier cancer detection and more effective cancer-directed treatments. ${ }^{11}$ However, survival from pancreatic cancer between 1950 and 1995 increased by only $3 \%$, contrasting with the improvements observed for several other cancers. ${ }^{10}$ Research in the Nordic countries has also indicated little change in pancreatic cancer survival between 1964 and 2006, and lowest survival among Danish patients. ${ }^{5,12}$ In 2000, the Danish government initiated the "National Cancer Plan I", with an update in 2005. The aims of the plan include enhancing cancer prevention; improving and accelerating the patient referral pathway; strengthening cancer surgery; monitoring cancer care; and implementing a multidisciplinary approach to diagnosis and treatment. ${ }^{13}$ It is critical to regularly monitor cancer patient survival to evaluate the effect of this cancer plan. In the current study therefore, we examined trends in mortality and survival of pancreatic cancer patients over time using Danish population and medical databases.

\section{Material and methods}

We conducted this study in the Central and the North Denmark Regions, with a combined population of 1.8 million persons, representing approximately one-third of the Danish population. The National Health Service provides tax-supported health care for all inhabitants of Denmark, guaranteeing free access to hospitals. Virtually no pancreatic cancer patients were treated in private hospitals during the study period.

We used the Danish National Patient Registry (DNPR) to identify the pancreatic cancer patients included in the current study. The DNPR contains information on all admissions from nonpsychiatric hospitals in Denmark since 1977, ${ }^{14}$ and outpatient and emergency room visits at these hospitals since 1995. The DNPR includes information on civil personal registration (CPR) number, dates of admission and discharge, surgical procedure(s) performed, and up to 20 diagnoses from each hospital contact. Diagnoses have been classified according to the International Classification of Diseases (ICD) 8th edition until the end of 1993 and 10th edition thereafter.

\section{Identification of pancreatic cancer patients}

We identified all patients who had an incident diagnosis of pancreatic cancer between January 1, 1998 and December 31,
2009 using the DNPR. We included all patients with an ICD-10 code of C25.x.

\section{Identification of pancreatic cancer surgery}

Surgical procedures have been classified according to a Danish classification system until the end of 1995 and according to a Danish version of the Nordic Classification of Surgical Procedures (NCSP) thereafter. We used the DNPR to identify the surgical procedures pancreatectomy (JLC.20), pancreatoduodenectomy (JLC.30), and total pancreatoduodenectomy (JLC.40) conducted within 90 days after the pancreatic cancer diagnosis.

\section{Survival}

Since 1968 the Danish Civil Registration System (DCRS) has assigned a unique 10-digit civil personal registration (CPR) number to all Danish citizens. ${ }^{15}$ This number, unique to each Danish resident, is used in all Danish registries, allowing unambiguous individual-level data linkage. From the DCRS we also obtained information on vital status (dead or alive), date of death, and residence for all cancer patients.

\section{Statistical analysis}

We followed each patient from the date of pancreatic cancer diagnosis until emigration, death, or 25 June 2010, whichever came first. We constructed Kaplan-Meier survival curves to illustrate crude survival stratified by diagnostic period (1998-2000, 2001-2003, 2004-2006, and 2007-2009). In the most recent periods we estimated 1-, 3-, and 5-year survival using a hybrid analysis whereby survival was estimated using the survival experience of patients in the previous periods. ${ }^{16} \mathrm{We}$ compared mortality over time using Cox proportional hazards regression analysis with 1998-2000 as the reference period to estimate 1-, 3- and 5-year mortality rate ratios (MRRs) and associated 95\% confidence intervals (CIs) adjusting for age group (15-59 years, 60-79 years, $\geq 80$ years), and gender.

Among patients who underwent surgery, we computed 30-day mortality rates from date of surgery for the four time periods. We used Cox proportional hazards regression analysis and estimated 30-day MRRs and associated 95\% CIs with 1998-2000 as the reference period, adjusting for age group and gender. We used the Cochran-Armitage trend test to evaluate the trend in 30-day mortality rates from 1998 through 2009. ${ }^{17}$

All analyses were performed using SAS version 9.2 (SAS Institute Inc., Cary, NC). 


\section{Results}

A total of 2968 patients was diagnosed with pancreatic cancer between 1998 and 2009 in the Central and North Denmark regions. The number of pancreatic cancer patients increased over the study period from 607 in 1998-2000 to 702 in 2001-2003, 768 patients in 2004-2006, and 891 patients in 2007-2009. Median age at diagnosis was 71 years and varied little by period of diagnosis (Table 1). Women were, on average, older at diagnosis than men and accounted for $51 \%$ of pancreatic cancer cases (Figure 1).

Figure 2 illustrates the survival curve of pancreatic cancer patients by period of diagnosis. Regardless of diagnostic period, less than $50 \%$ of patients were alive at 6 months after diagnosis. Median survival was 2.7 months for patients diagnosed in 1998-2000; 2.8 months for patients diagnosed in 2001-2003; 3.2 months for those diagnosed in 2004-2006 and 2007-2009. Table 1 also outlines the cumulative proportion of patients surviving at 1, 3, and 5 years, as well as the crude and adjusted MRRs by diagnostic period, using patients diagnosed in the earliest period (1998-2000) as a reference group. Patients diagnosed in 2004-2006 and 2007-2009 had slightly better survival 1-year post-diagnosis than those in the earlier periods $(17.4 \%, 95 \% \mathrm{CI}=14.9 \%, 20.2 \%$, and $17.7 \%$, $95 \% \mathrm{CI}=15.3 \%, 20.4 \%$, versus $14.8 \%, 95 \% \mathrm{CI}=12.1 \%$, $17.8 \%$ and $15.1,95 \% \mathrm{CI}=12.6 \%, 17.9 \%$, respectively). The projected estimates for 3- and 5-year survival also increased from $3.5 \%(95 \% \mathrm{CI}=2.2 \%, 5.1 \%)$ to $5.6 \%(95 \% \mathrm{CI}=4.2 \%$, $7.4 \%)$ and from $2.0 \%(95 \% \mathrm{CI}=1.1 \%, 3.3 \%)$ to $3.8 \%(95 \%$ $\mathrm{CI}=2.6 \%, 5.4 \%$ ), respectively, over the study period.

Table 2 outlines the cumulative survival at 1, 3, and 5 years stratified by age and gender. One-year survival appeared to be best in the youngest age group, ranging from $19.7 \%(95 \% \mathrm{CI}=11.2 \%, 30.0 \%)$ to $27.5 \%(95 \% \mathrm{CI}=16.4 \%$, $19.9 \%$ ) in women. One-year survival was lower in women aged 60-79 years (range $13.1 \%, 95 \% \mathrm{CI}=8.8 \%, 18.1 \%$, to $17.9 \%, 95 \% \mathrm{CI}=13.1 \%, 23.3 \%$ ), and was lowest in elderly patients (age $80+$ ) - range $8.2 \%, 95 \% \mathrm{CI}=3.8 \%, 14.6 \%$ to $10 \%, 95 \% \mathrm{CI}=4.7 \%, 17.7 \%)$. There was little change in 3- and 5-year survival estimates from 1998 through 2009. The same pattern was evident among male pancreatic cancer patients, where the cumulative proportion of men surviving 1-year after diagnosis was highest in the youngest age group, lower in the middle age group and lowest in the elderly patients.

A total of 176 pancreatic cancer patients was surgically treated within 90 days after diagnosis, accounting for a mere $5.9 \%$ of the total patient population. The median age of surgical patients was lower than that of nonsurgical patients (surgical patients median age 62.4 compared with a median age of 71.8 in nonsurgical patients). Surgical patients were slightly older in the latter two diagnostic periods than those diagnosed between 1998 and 2003. The 30-day mortality after surgery was approximately halved after the first period 1998-2001 from $12.2 \%$ to $6.8 \%, 5.1 \%$ and $5.8 \%$, corresponding to an age-adjusted MRR of $0.38(95 \% \mathrm{CI}=0.09,1.6)$ in the last period compared with the first period (Table 3) (2-sided $P$-value $=0.26$ ).

\section{Discussion}

This study shows that survival of pancreatic cancer patients in Denmark marginally improved between 1998 and 2009. Although only a modest improvement, pancreatic cancer

Table I Cumulative survival and crude and adjusted relative mortality (MRR) (and associated 95\% confidence intervals) for pancreatic cancer patients diagnosed in Central and Northern Denmark, 1998-2009

\begin{tabular}{|c|c|c|c|c|}
\hline & \multicolumn{4}{|l|}{ Year of diagnosis } \\
\hline & | 998-2000 & $200 I-2003$ & 2004-2006 & 2007-2009 \\
\hline Number of cancer patients & 607 & 702 & 768 & 891 \\
\hline Median age (years) & 72 & 71 & 71 & 71 \\
\hline \multicolumn{5}{|l|}{ I-year } \\
\hline Survival & $14.8 \%(12.1 \%-17.8 \%)$ & $15.1 \%(12.6 \%-17.9 \%)$ & $17.4 \%(14.9 \%-20.2 \%)$ & $17.7 \%(15.3 \%-20.4 \%)$ \\
\hline Relative mortality & I (reference) & $0.98(0.87-1.10)$ & $0.88(0.78-0.99)$ & $0.88(0.79-0.99)$ \\
\hline Adjusted relative mortality ${ }^{a}$ & I (reference) & $0.98(0.87-I . I I)$ & $0.87(0.77-0.98)$ & $0.86(0.77-0.96)$ \\
\hline \multicolumn{5}{|l|}{ 3-year } \\
\hline Survival & $3.5 \%(2.2 \%-5.1 \%)$ & $3.6 \%(2.4 \%-5.1 \%)$ & $5.1 \%(3.7 \%-6.8 \%)$ & $5.6 \%(4.2 \%-7.4 \%)^{b}$ \\
\hline Relative mortality & I (reference) & $0.98(0.87-1.09)$ & $0.87(0.78-0.97)$ & $0.87(0.78-0.96)^{\mathrm{b}}$ \\
\hline Adjusted relative mortality ${ }^{a}$ & I (reference) & $0.97(0.87-1.09)$ & $0.86(0.77-0.96)$ & $0.84(0.75-0.93)^{b}$ \\
\hline \multicolumn{5}{|l|}{ 5-year } \\
\hline Survival & $2.0 \%(1.1 \%-3.3 \%)$ & $2.1 \%(1.3 \%-3.4 \%)$ & $3.4 \%(2.3 \%-4.9 \%)^{b}$ & $3.8 \%(2.6 \%-5.4 \%)^{b}$ \\
\hline Relative mortality & I (reference) & $0.98(0.88-1.09)$ & $0.87(0.78-0.97)^{\mathrm{b}}$ & $0.86(0.78-0.96)^{\mathrm{b}}$ \\
\hline Adjusted relative mortality ${ }^{a}$ & I (reference) & $0.97(0.87-I .08)$ & $0.85(0.76-0.95)^{\mathrm{b}}$ & $0.83(0.75-0.92)^{\mathrm{b}}$ \\
\hline
\end{tabular}

Notes: aAdjusted for age and gender; bPredicted values. 

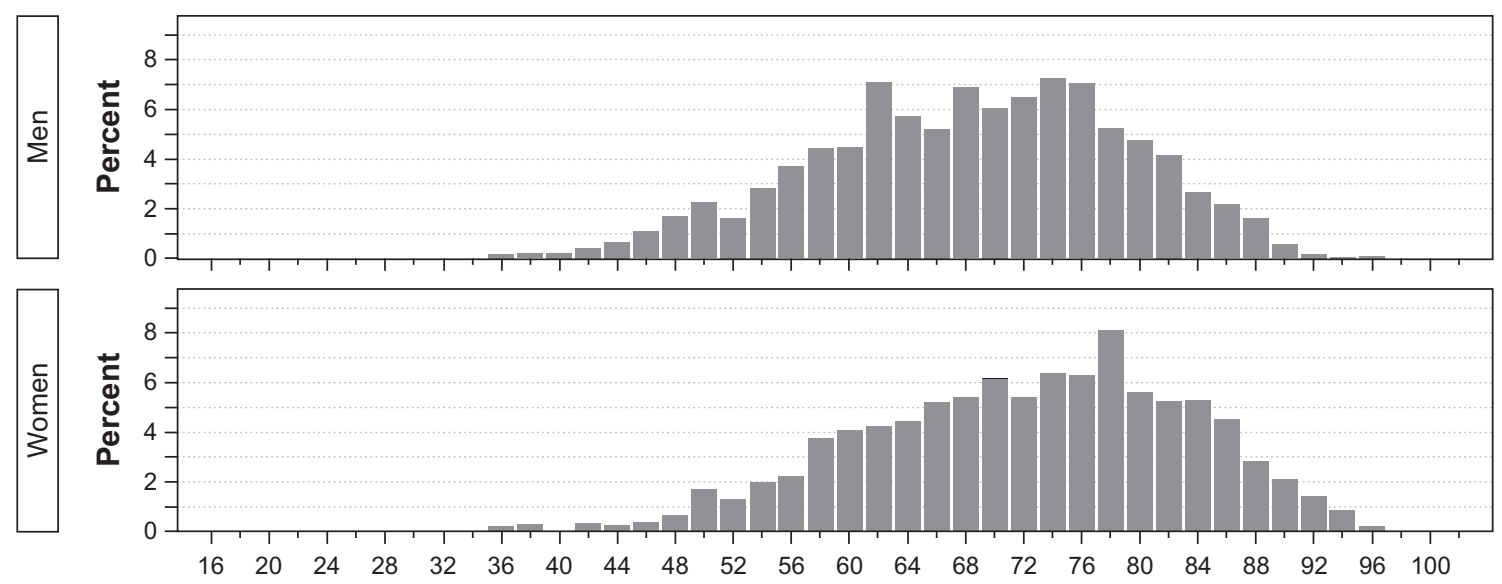

Figure I Age at diagnosis of pancreatic cancer patients in Central and Northern Denmark 1998-2009 by gender.

has such a low median survival, that any improvement is noteworthy. There was also a decline in 30-day mortality after surgery for pancreatic cancer, likely attributable to increasing centralization of cancer services and a multidisciplinary approach to cancer treatment. ${ }^{18}$

When interpreting our findings several factors should be considered. The large size and uniformly organized health care system facilitated a population-based design with accurate survival estimates, and reduced selection bias. The use of the DCRS ensured complete follow-up. ${ }^{15}$ We used the DNPR rather than the Danish Cancer Registry to obtain information on individuals with pancreatic cancer due to the delay in reporting of cancer cases to the cancer registry. As the DNPR is continuously updated, it provided an ideal setting in which to monitor any recent changes in survival. Furthermore, the sensitivity and positive predictive value of a cancer diagnosis in the DNPR is high, increasing the validity of our study. ${ }^{14,19,20}$ Presentation of estimates of survival and mortality make the findings from this study suitable for comparison with findings from other countries. Our study also serves to highlight that data from patient registries are suitable tools to use when monitoring cancer survival.

Improvements in pancreatic cancer survival could be facilitated by detecting the cancer before local invasion or distant metastatic disease is established - when surgery is most effective. An increase in the proportion of patients with localized disease would also improve the selection of surgical candidates, thereby improving surgical outcomes.

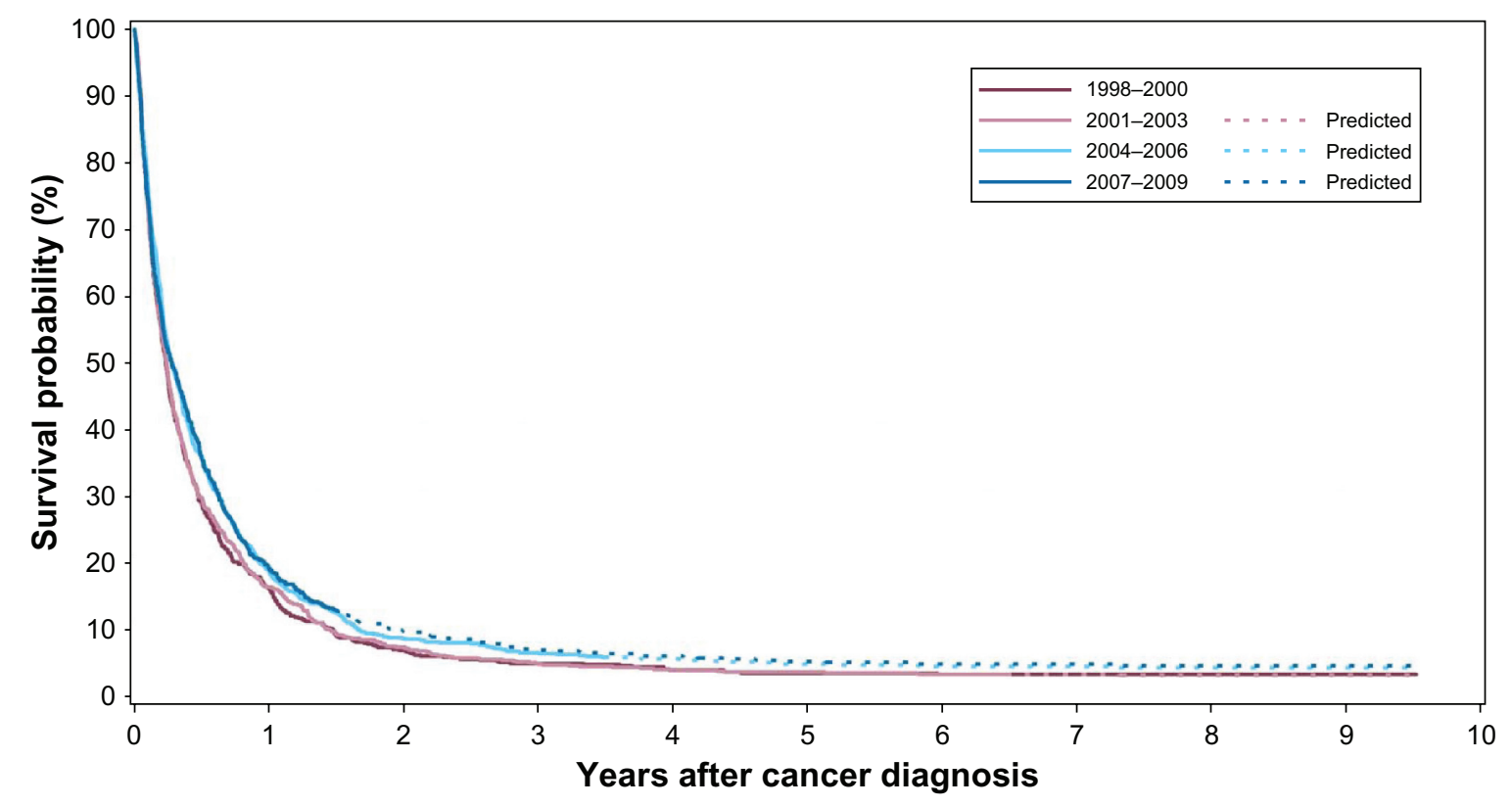

Figure 2 Kaplan-Meier survival curves for patients with pancreatic cancer in Central and Northern Denmark regions, $1998-2009$. 
Table 2A Cumulative survival (and associated 95\% confidence intervals) for male pancreatic cancer patients diagnosed in Central and Northern Denmark, 1998-2009

\begin{tabular}{|c|c|c|c|c|}
\hline \multirow{2}{*}{$\begin{array}{l}\text { Men } \\
\text { age (years) }\end{array}$} & \multicolumn{4}{|l|}{ Year of diagnosis } \\
\hline & $1998-2000$ & $200 I-2003$ & 2004-2006 & 2007-2009 \\
\hline \multicolumn{5}{|l|}{$15-59$} \\
\hline Number of cancer patients & 78 & 82 & 86 & 82 \\
\hline I-year survival & $24.4 \%(15.5 \%-34.3 \%)$ & $18.3 \%(10.8 \%-27.3 \%)$ & $30.2 \%(20.9 \%-40.1 \%)$ & $24.0 \%(15.3 \%-33.7 \%)$ \\
\hline 3-year survival & $9.0 \%(3.9 \%-16.6 \%)$ & $7.3 \%(3.0 \%-14.3 \%)$ & $10.5 \%(5.1 \%-18.0 \%)$ & $7.7 \%(3.3 \%-14.4 \%)^{\mathrm{a}}$ \\
\hline 5-year survival & $7.7 \%(3.1 \%-14.9 \%)$ & $6.1 \%(2.3 \%-12.7 \%)$ & $8.3 \%(3.7 \%-15.2 \%)^{\mathrm{a}}$ & $6.1 \%(2.4 \%-12.1 \%)^{a}$ \\
\hline \multicolumn{5}{|l|}{$60-79$} \\
\hline Number of cancer patients & 170 & 225 & 249 & 277 \\
\hline I-year survival & $11.2 \%(7.0 \%-16.4 \%)$ & $18.2 \%(13.5 \%-23.5 \%)$ & $17.3 \%(12.9 \%-22.2 \%)$ & $20.5 \%(15.9 \%-25.6 \%)$ \\
\hline 3-year survival & $1.8 \%(0.5 \%-4.7 \%)$ & $2.7 \%(1.1 \%-5.4 \%)$ & $5.6 \%(3.2 \%-9.0 \%)$ & $7.0 \%(4.2 \%-10.7 \%)^{\mathrm{a}}$ \\
\hline 5-year survival & $0.6 \%(0.1 \%-3.0 \%)$ & $0.4 \%(0.0 \%-2.3 \%)$ & $3.3 \%(1.5 \%-6.2 \%)^{\mathrm{a}}$ & $4.1 \%(1.9 \%-7.6 \%)^{a}$ \\
\hline \multicolumn{5}{|l|}{$80+$} \\
\hline Number of cancer patients & 45 & 50 & 60 & 63 \\
\hline I-year survival & $8.9 \%(2.8 \%-19.3 \%)$ & $6.0 \%(1.6 \%-14.9 \%)$ & $8.3 \%(3.1 \%-17.0 \%)$ & $14.3 \%(7.0 \%-24.0 \%)$ \\
\hline 3-year survival & $0 \%$ & $0 \%$ & $3.3 \%(0.6 \%-10.2 \%)$ & $3.5 \%(0.7 \%-10.3 \%)^{\mathrm{a}}$ \\
\hline 5-year survival & $0 \%$ & $0 \%$ & - & - \\
\hline
\end{tabular}

Note: aPredicted values.

The National Cancer Strategy may have contributed to the detection and diagnosis of pancreatic cancer at an earlier stage. Unfortunately, we had no information on clinical characteristics such as cancer stage at diagnosis and cancerdirected treatment, other than cancer surgery. Therefore, we were unable to investigate the impact of these factors on pancreatic cancer survival and how possible changes in these factors may correlate with the observed changes in survival.

Although pancreatic cancer is frequently resistant to chemotherapy, randomized trials have shown that chemotherapy can be beneficial in selected groups of patients, particularly those who undergo surgical resection. ${ }^{21}$ The majority of pancreatic cancer patients are elderly when diagnosed, and therefore may be considered unlikely to respond to treatment or unable to tolerate aggressive cancer-directed treatments.

Pancreatectomy is considered a complex and technically challenging procedure due to the location and inaccessibility of the pancreas. ${ }^{22}$ Research suggests the procedure is underutilized in clinical practice. ${ }^{23}$ The proportion of patients undergoing pancreatectomy in the current study was similar to rates observed in Ireland $(7 \%)^{24}$ and Scotland $(5 \%),{ }^{25}$ but much lower than rates in Sweden $(15 \%),{ }^{26}$ the Netherlands $(11 \%),{ }^{27}$ and the US $(\sim 15 \%)^{28,29}$ over comparable

Table 2B Cumulative survival (and associated 95\% confidence intervals) for female pancreatic cancer patients diagnosed in Central and Northern Denmark, 1998-2009

\begin{tabular}{|c|c|c|c|c|}
\hline \multirow{2}{*}{$\begin{array}{l}\text { Women } \\
\text { age (years) }\end{array}$} & \multicolumn{4}{|l|}{ Year of diagnosis } \\
\hline & $1998-2000$ & $2001-2003$ & 2004-2006 & 2007-2009 \\
\hline \multicolumn{5}{|l|}{$15-59$} \\
\hline Number of cancer patients & 63 & 66 & 57 & 57 \\
\hline I-year survival & $25.4 \%(15.5 \%-36.6 \%)$ & $19.7 \%(11.2 \%-30.0 \%)$ & $22.8 \%(13.0 \%-34.3 \%)$ & $27.5 \%(16.4 \%-39.9 \%)$ \\
\hline 3-year survival & $7.9 \%(2.9 \%-16.2 \%)$ & $4.5 \%(1.2 \%-11.5 \%)$ & $10.5 \%(4.3 \%-20.0 \%)$ & $8.2 \%(2.1 \%-20.0 \%)^{\mathrm{a}}$ \\
\hline 5-year survival & $6.3 \%(2.0 \%-\mid 4.2 \%)$ & - & $8.8 \%(3.3 \%-17.9 \%)^{\mathrm{a}}$ & $6.6 \%(1.5 \%-17.2 \%)^{\mathrm{a}}$ \\
\hline \multicolumn{5}{|l|}{$60-79$} \\
\hline Number of cancer patients & 170 & 199 & 218 & 276 \\
\hline I-year survival & $14.1 \%(9.4 \%-19.8 \%)$ & $13.1 \%(8.8 \%-\mid 8.1 \%)$ & $17.9 \%(13.1 \%-23.3 \%)$ & $16.4 \%(12.2 \%-21.1 \%)$ \\
\hline 3-year survival & $2.9 \%(1.1 \%-6.3 \%)$ & $3.5 \%(1.6 \%-6.8 \%)$ & $3.2 \%(1.4 \%-6.2 \%)$ & $6.2 \%(3.6 \%-9.7 \%)^{\mathrm{a}}$ \\
\hline 5-year survival & $0 \%$ & $3.0 \%(1.2 \%-6.1 \%)$ & $1.8 \%(0.6 \%-4.3 \%)^{a}$ & $3.6 \%(1.5 \%-7.3 \%)^{a}$ \\
\hline \multicolumn{5}{|l|}{$80+$} \\
\hline Number of cancer patients & 81 & 80 & 98 & 136 \\
\hline I-year survival & $9.9 \%(4.6 \%-17.5 \%)$ & $10.0 \%(4.7 \%-17.7 \%)$ & $8.2 \%(3.8 \%-\mid 4.6 \%)$ & $8.6 \%(4.6 \%-\mid 4.1 \%)$ \\
\hline 3-year survival & $1.2 \%(0.1 \%-6.0 \%)$ & $3.8 \%(1.0 \%-9.6 \%)$ & $1.0 \%(0.1 \%-5.0 \%)$ & $0.9 \%(0.1 \%-4.3 \%)^{\mathrm{a}}$ \\
\hline 5-year survival & - & $0 \%$ & - & - \\
\hline
\end{tabular}

Note: aPredicted values. 
Table 3 30-day mortality and relative mortality (and associated $95 \%$ confidence intervals) among pancreatic cancer patients diagnosed in Central and Northern Denmark, 1998-2009

\begin{tabular}{|c|c|c|c|c|}
\hline & \multicolumn{4}{|l|}{ Year of surgery } \\
\hline & $1998-2000$ & $200 \mathrm{I}-2003$ & 2004-2006 & 2007-2009 \\
\hline Number of cancer patients & 41 & 44 & 39 & 52 \\
\hline Median age (years) & 61 & 59 & 63 & 65 \\
\hline 30-day mortality & $12.2 \%(5.3 \%-26.8 \%)$ & $6.8 \%(2.3 \%-19.7 \%)$ & $5.1 \%(1.3 \%-19.0 \%)$ & $5.8 \%(1.9 \%-16.8 \%)$ \\
\hline 30-day relative mortality & I (reference) & $0.53(0.13-2.20)$ & $0.4 I(0.08-2.10)$ & $0.45(0.1 \mathrm{I}-\mathrm{I} .88)$ \\
\hline 30-day relative mortality ${ }^{\mathrm{a}}$ & I (reference) & $0.59(0.14-2.5 \mathrm{I})$ & $0.37(0.07-1.98)$ & $0.38(0.09-1.63)$ \\
\hline
\end{tabular}

Note: adjusted for age and gender.

diagnostic periods. Reasons for such variation in surgical rates are not clear. We incorporated information on surgery within 90 days of diagnosis; the US study incorporated surgery within 120 days; and the Irish study, based on cancer registry data, included surgeries registered within the first year after diagnosis. These differences may account for the variation in surgical rates across these countries, however given the poor survival of pancreatic cancer; it is likely that surgery with a curative intent would be given soon after diagnosis. The difference in surgical rates may also be due to the fact that patients with localized stage are considered the only potentially curable patients, and international studies have shown a more advanced stage distribution among Danish cancer patients, generally, than in other developed countries with comparable health care systems. ${ }^{30}$ Nonetheless, despite the relatively low uptake of surgery, in these Danish pancreatic cancer patients we saw a decrease in postoperative mortality consistent with trends reported in the Nordic countries ${ }^{5}$ and elsewhere. ${ }^{31-33}$ This lower mortality may reflect the implementation of the National Cancer Plan, specifically strengthening and centralization of surgery, and a more multidisciplinary approach to cancer treatment. ${ }^{18}$

Furthermore, the National Cancer Plan also aims to improve cancer diagnostics through increasing the availability of cancer scanners, for example. This may have created a "lead-time bias" in the current study, whereby patients are diagnosed at an earlier stage and so their survival appears longer. Unfortunately, we did not have information on cancer stage and so we are unable to explore this possibility further.

Smoking is one of the few established risk factors for pancreatic cancer, others being type 2 diabetes and chronic pancreatitis. ${ }^{34}$ It has been estimated that smoking prevention could decrease the incidence of pancreatic cancer by as much as $20 \%{ }^{6}$ Due to the poor prognosis of the disease, cancer prevention may be the only way to reduce the disease burden in the population. However, the relatively occult nature of pancreatic cancer etiology means that population-based survival and relative mortality, such as presented in the current study, are likely to remain key indicators of progress against this deadly disease.

In conclusion, this study shows a very slight improvement in pancreatic cancer survival and decreased relative mortality. These findings are consistent with findings for the Danish cancer patient population generally, ${ }^{5,12}$ and are likely to be a direct effect of the dissemination of the National Cancer Plan. However, the poor prognosis of this disease means that efforts at preventing, diagnosing and treating this disease need to be intensified in order to continue to improve survival.

\section{Acknowledgments}

The study received financial support from the Karen Elise Jensen Foundation, Department of Clinical Epidemiology's Research Foundation and the Regional Clinical Epidemiological Monitoring Initiative for Central and North Denmark Regions.

\section{Disclosure}

The authors report no conflicts of interest.

\section{References}

1. Ferlay J, Shin HR, Bray F, et al. Estimates of worldwide burden of cancer in 2008: GLOBOCAN 2008. Int J Cancer. 2010;127:2893-2917.

2. Sundhedsstyrelsen. Cancer Incidence in Denmark in 2009; 2010.

3. Sundhedsstyrelsen. Danish Cause of Death in 2009; 2010.

4. Holly EA, Chaliha I, Bracci PM, et al. Signs and symptoms of pancreatic cancer: a population-based case-control study in the San Francisco Bay area. Clin Gastroenterol Hepatol. 2004;2:510-517.

5. Klint A, Engholm G, Storm HH, et al. Trends in survival of patients diagnosed with cancer of the digestive organs in the Nordic countries 1964-2003 followed up to the end of 2006. Acta Oncol. 2010;49: 578-607.

6. Teiblum S, Thygesen LC, Johansen C. Sixty-one years of pancreatic cancer in Denmark from 1943 to 2003: a nationwide study. Pancreas. 2009;38:374-378.

7. Nagenthiraja K, Ewertz M, Engholm G, et al. Incidence and mortality of pancreatic cancer in the Nordic countries 1971-2000. Acta Oncol. 2007; 46:1064-1069.

8. Michalski CW, Weitz J, Buchler MW. Surgery insight: surgical management of pancreatic cancer. Nat Clin Pract Oncol. 2007;4:526-535.

9. Bergenfeldt M, Hansen CP, Mortensen MB. Surgical treatment of pancreatic cancer. Ugeskr Laeger. 2010;172:1358-1360. 
10. Welch HG, Schwartz LM, Woloshin S. Are increasing 5-year survival rates evidence of success against cancer? JAMA. 2000;283:2975-2978.

11. Jemal A, Clegg LX, Ward E, et al. Annual report to the nation on the status of cancer, 1975-2001, with a special feature regarding survival. Cancer. 2004;101:3-27.

12. Coleman MP, Forman D, Bryant H, et al. Cancer survival in Australia, Canada, Denmark, Norway, Sweden, and the UK, 1995-2007 (the International Cancer Benchmarking Partnership): an analysis of population-based cancer registry data. Lancet. 2001;377:127-138.

13. Sundhedsstyrelsen. National kræftplan. Status og forslag til initiativer i relation til kræftbehandlingen. 1-161 (Sundhedsstyrelsen, København, 2000).

14. Andersen TF, Madsen M, Jorgensen J, et al. The Danish National Hospital Register. A valuable source of data for modern health sciences. Dan Med Bull. 1999;46:263-268.

15. Pedersen CB, Gotzsche H, Moller JO, et al. The Danish Civil Registration System. A cohort of eight million persons. Dan Med Bull. 2006;53: 441-449.

16. Brenner H, Rachet B. Hybrid analysis for up-to-date long-term survival rates in cancer registries with delayed recording of incident cases. Eur J Cancer. 2004;40:2494-2501.

17. Agresti A. Categorical Data Analysis. New York, NY: John Wiley and Sons, Inc.; 1990

18. Storm HH, Gislum M, Engholm G. Cancer survival before and after initiating the Danish Cancer Control plan. Ugeskr Laeger. 2008;170 3065-3069.

19. Tetsche MS, Norgaard M, Skriver MV, et al. Accuracy of ovarian cancer ICD-10 diagnosis in a Danish population-based hospital discharge registry. Eur J Gynaecol Oncol. 2005;26:266-270.

20. Norgaard M, SkriverMV, Gregersen H, et al. The data quality of haematological malignancy ICD-10 diagnoses in a population-based hospital discharge registry. Eur J Cancer Prev. 2005;14:201-206.

21. Yip D, Karapetis C, Strickland A, et al. Chemotherapy and radiotherapy for inoperable advanced pancreatic cancer. Cochrane Database Syst Rev. 2006;3:CD002093.

22. Shaib Y, Davila J, Naumann C, et al. The impact of curative intent surgery on the survival of pancreatic cancer patients: a US Populationbased study. Am J Gastroenterol. 2007;102:1377-1382.
23. Eloubeidi MA, Desmond RA, Wilcox CM, et al. Prognostic factors for survival in pancreatic cancer: a population-based study. Am J Surg. 2006;192:322-329.

24. Sharp L, Carsin AE, Cronin-Fenton DP, et al. Is there under-treatment of pancreatic cancer? Evidence from a population-based study in Ireland. Eur J Cancer. 2009;45:1450-1459.

25. Parks RW, Bettschart V, Frame S, et al. Benefits of specialisation in the management of pancreatic cancer: results of a Scottish populationbased study. Br J Cancer. 2004;91:459-465.

26. Linder S, Bostrom L, Nilsson B. Pancreatic cancer in sweden 1980-2000: a population-based study of hospitalized patients concerning time trends in curative surgery and other interventional therapies. $J$ Gastrointest Surg. 2006;10:672-678.

27. Van Oost FJ, Luiten EJ, van de Poll-Franse LV, et al. Outcome of surgical treatment of pancreatic, peri-ampullary and ampullary cancer diagnosed in the south of The Netherlands: a cancer registry based study. Eur J Surg Oncol. 2006;32:548-552.

28. Shavers VL, Harlan LC, Jackson M, et al. Racial/ethnic patterns of care for pancreatic cancer. J Palliat Med. 2009;12:623-630.

29. Cress RD, Yin D, Clarke L, et al. Survival among patients with adenocarcinoma of the pancreas: a population-based study (United States) Cancer Causes Control. 2006;17:403-409.

30. Storm HH, Dickman PW, Engeland A, et al. Do morphology and stage explain the inferior lung cancer survival in Denmark? Eur Respir J. 13:430-435.

31. Schmidt CM, Choi J, Powell ES, et al. Pancreatic fistula following pancreaticoduodenectomy: clinical predictors and patient outcomes. HPB Surg. 2009:404520.

32. Nakeeb A, Lillemoe KD, Grosfeld JL. Surgical techniques for pancreatic cancer. Minerva Chir. 2004;59:151-163.

33. Geer RJ, Brennan MF. Prognostic indicators for survival after resection of pancreatic adenocarcinoma. Am J Surg. 1993;165:68-72; discussion $72-63$.

34. Maisonneuve P, Lowenfels AB. Epidemiology of pancreatic cancer: an update. Dig Dis. 2010;28:645-656.
Clinical Epidemiology

\section{Publish your work in this journal}

Clinical Epidemiology is an international, peer-reviewed, open access journal focusing on disease and drug epidemiology, identification of risk factors and screening procedures to develop optimal preventative initiatives and programs. Specific topics include: diagnosis, prognosis, treatment, screening, prevention, risk factor modification, systematic

\section{Dovepress}

reviews, risk \& safety of medical interventions, epidemiology \& biostatical methods, evaluation of guidelines, translational medicine, health policies \& economic evaluations. The manuscript management system is completely online and includes a very quick and fair peer-review system, which is all easy to use. 